\title{
PESQUISA E PRÁTICA DE ENSINO EM GEOGRAFIA: PRODUÇÃO TEXTUAL AUTORAL E AUTONOMIZAÇÃO DE SABERES
}

\section{Research and practice of teaching in geography: Authorial production and autonomization of knowledge}

\author{
Luyanne Catarina Lourenço de Azevedo \\ Mestranda pelo programa de pós-graduação em Geografia da UERJ-FFP \\ luyanne.azevedo@gmail.com \\ Denizart da Silva Fortuna \\ Professor do Depto. de Sociedade, Educação e Conhecimento da UFF \\ denizart.fortuna@id.uff.br
}

Artigo enviado para publicação em 21/03/2019 e aceito em 17/06/2019

DOI: $10.12957 /$ tamoios.2019.40933

\begin{abstract}
Resumo
A produção textual autoral foi uma das atividades desenvolvidas na monitoria e nos estágios de Pesquisa e Prática de Ensino em Geografia II e IV, compreendendo que tal produção é condição essencial para o processo formativo de futuros professores. Além da mediação do conhecimento geográfico, confeccionar tais textos cumpre a função de recurso pedagógico para as/os próprias/os licenciandas/os nesses estágios. $\mathrm{O}$ foco foi apresentar a produção de textos didáticos autorais enquanto possibilidade de (re)criação de sentidos e conceitos diante das diferentes realidades escolares por meio de múltiplas linguagens. Desta forma, o objetivo central do trabalho foi refletir sobre as práticas pedagógicas e os respectivos referenciais teóricos para a produção da geografia escolar a partir da produção autoral discente. Com livre escolha referente aos gêneros discursivos, as/os discentes analisaram distintas obras didáticas e paradidáticas para a elaboração dos seus textos, tendo em mente que conceitos carregam significados, e que esta produção requer, além da pesquisa, atenção para o tipo de discurso presentes nos materiais. $\mathrm{O}$ incentivo a esta experiência se faz essencial, uma vez que a partir de realidades escolares diversas desenvolve-se a autonomia necessária para a elaboração de conteúdos curriculares contextualizados.
\end{abstract}

Palavras-chave: Linguagens, Produção autoral, Textualidade.

\begin{abstract}
The author's textual production was one of the activities developed in the monitoring and in the stages of Research and Practice of Teaching in Geography II and IV, understanding that such production is an essential condition for the formative process of future teachers. In addition to the mediation of geographic knowledge, making such texts fulfills the function of pedagogical resource for the own / the graduates / those in these stages. The focus was to present the production of copywriting texts as a possibility of (re) creation of meanings and concepts in the face of different school realities through multiple languages. In this way, the main objective of the work was to reflect on the pedagogical practices and the respective theoretical references for the production of the school geography from the student authoring production. With free choice regarding discursive genres, the students analyzed different didactic and paradidical works for the elaboration of their texts, bearing in mind which concepts carry meanings, and that this production requires, besides the research, attention to the type of discourse present materials. The incentive to this experience becomes essential, since from diverse school realities the autonomy necessary for the elaboration of contextualised curricular contents develops.
\end{abstract}

Keywords: Languages, Authorial production, Textuality. 


\section{Introdução}

O presente trabalho é fruto das atividades desenvolvidas na monitoria dos componentes curriculares de Pesquisa e Prática de Ensino de Geografia II e IV (PPE), estágio dos licenciados de Geografia do Instituto de Geociências da Universidade Federal Fluminense - Niterói. Desempenhadas ao longo do ano primeiro semestre do período letivo de 2017, as atividades escolhidas para este artigo referem-se às produções textuais autorais realizadas por discentes da disciplina.

Compreende-se que o professor em sua prática cotidiana, no momento em que elabora e desenvolve conteúdos escolares, é produtor de conhecimento e de novos marcos epistemológicos. As/os docentes estão a todo o tempo produzindo discursos que se reproduzem por meio da linguagem: seja verbal, gestual, escrita, visual - ou de qualquer outro tipo. De acordo com Carvalho (2002) e Barreto (2010), partimos do pressuposto que a linguagem é múltipla e diversa e está presente em qualquer espaço educativo, haja vista que essa ação pressupõe a produção de significação.

Barreto (2010, p. 216) salienta ainda que na instituição escolar "[...] a presença de múltiplas linguagens constitui uma alternativa de ruptura com os limites impostos pelas velhas tecnologias utilizadas e representadas, principalmente pelos livros didáticos [...]". É importante, desta forma, elucidar que o nosso foco não é uma crítica formal ao livro didático e sim apresentar a produção de textos didáticos autorais enquanto possibilidade a (re) criação de sentidos e de conceitos diante das diferentes realidades escolares. Para tanto, a concepção de docentes sobre as potencialidades dessa produção é determinante.

Diante de discussões e leituras prévias realizadas com discentes que cursaram as disciplinas, indagou-se durante os Estágios de Pesquisa e Prática de Ensino em Geografia: por que ainda persiste a ideia de que professores reproduzem/transmitem o conhecimento advindo da academia e não produzem conhecimento/saber escolar? Por que professores da educação básica, na maioria das vezes, encontram dificuldades para produzir os seus próprios materiais didáticos? Estas foram algumas das questões levantadas para as reflexões dentro de sala de aula, e desta forma, não buscamos respondê-las neste artigo.

Nesse sentido, uma das atividades propostas nos estágios de Pesquisa e Prática de ensino (PPE) II e IV em Geografia foi a produção textual autoral por parte das/os discentes. A confecção dos materiais didáticos foi um exercício que visou instigar, de forma crítica, os discursos presentes nas mais diversas textualidades utilizadas dentro do espaço escolar, problematizando o fazer pedagógico a partir de leituras que proporcionaram diferentes reflexões a respeito da produção de conhecimento, de conteúdos escolares e de materiais didáticos. Segundo Carvalho (2002) no espaço escolar há a todo o momento a presença, a produção e reprodução de discursos por meio das mais diversas linguagens.

Assim, este trabalho teve como objetivos: (1) Refletir sobre as práticas pedagógicas e os respectivos referenciais teóricos para a produção da geografia escolar a partir da produção autoral discente; (2) exercitar a leitura crítica por meio de uma produção autoral atenta à linguagem e ao discurso; (3) estimular a produção textual autoral reflexiva e crítica por parte das alunas e alunas de PPE II e IV e da monitora; (4) a inserção da monitora na prática pedagógica de formação de professores do Curso de Graduação de Geografia, a partir de reflexões e leituras relacionadas à temática; 
Percursos, caminhos e linhas - nem sempre retilíneas - das escritas e fazeres autorais

Compreende-se neste artigo que um dos papeis da Geografia Escolar é a construção dialógica de percepções e leituras do mundo por intermédio da realidade vivida pelas alunas e alunos em suas práticas espaciais cotidianas, além da percepção da espacialidade destas práticas e de suas relações sociais (CAVALCANTI, 2012; CALLAI, 2015). Outro papel da Geografia Escolar que entendemos não apenas neste trabalho, mas nas práticas cotidianas, é a construção de uma leitura de mundo voltada para a cidadania e uma sociedade plural.

Segundo Bezerra (2016) e Costa (2011) a cidadania possui um papel fundamental dentro do ensino, para que alunas e alunos construam uma consciência espacial, compreendendo assim a sociedade, a cidadania, as relações socioespaciais e seus próprios papéis enquanto agentes na produção do espaço e de suas relações e práticas sociais e espaciais. Observa-se ainda a importância da contribuição para uma consciência crítica e criativa quanto nas cidadãs e cidadãos:

Por tanto, se asume a la realidad vivida como objeto de estudio con la finalidad de contribuir a forjar La conciencia crítica y creativa en ciudadanos en el ámbito de la complejidad del lugar habitado y gestionar opciones factibles de generar cambios significativos hacia La formación democrática. (RIVERA, 2015, p. 3)

A dimensão espacial é, portanto, extremamente necessária nas práticas e reflexões dentro do universo escolar e na Geografia que se ensina. É por meio do espaço que se dá a possibilidade de estudantes construírem - além reconhecerem - as suas identidades e o seu pertencimento no mundo, sendo a Geografia disciplina que procura construir ferramentas teóricas para esta compreensão e reconhecimento do mundo, da espacialidade e dos fenômenos sociais (CALLAI, 2015). Já de acordo com Rivera (2015) é fundamental direcionar a ação pedagógica para as necessidades da sociedade:

[...] es imprescindible prestar atención a las situaciones vividas del escenario geohistórico y social, donde se desenvuelve La habitualidad de la acción y el protagonismo ciudadano. Se trata de reconocer el lugar que habita el colectivo social, pues es allí donde se vincula con sus coterráneos en su mismo território [...] (RIVERA, 2015, p. 7)

Assim, a partir de discussões e debates realizados em sala de aula - e que perpassaram pela ideia de um Ensino de Geografia voltado para a pluralidade, cidadania e para o que chamaremos aqui de uma Geografia Escolar das diferenças, a atividade proposta no componente curricular Pesquisa e Prática de Ensino (PPE) em Geografia II e IV foi a confecção de um texto didático. Para as turmas de PPE II o fio condutor da produção autoral das alunas e alunos foi referente aos componentes curriculares de Geografia trabalhados no $2^{\circ}$ segmento do Ensino Fundamental $\left(6^{\circ}\right.$ ao $9^{\circ}$ anos), pois neste estágio abordam-se questões acerca das práticas curriculares e do currículo de Geografia. Já para as alunas e alunos das turmas de PPE IV, a temática abordada foram as diversidades e diferenças numa perspectiva geográfica, pois as reflexões acerca da representação social e das diferenças estão presentes neste estágio.

Balizado por levantamento bibliográfico relativo à produção autoral docente e tendo a linguagem como conceito chave a ser trabalhado, o desenvolvimento das atividades ocorreu durante o primeiro semestre letivo de 2017. O passo seguinte se deu em quatro aulas co-ministradas com o professor e orientador no primeiro e semestre do referido ano letivo, com o esforço de identificar os sentidos dos conceitos presentes em 
textos didáticos de Geografia e a sua relação à cultura acadêmica. Em seguida, por meio de uma atividade em grupo e com a livre escolha referente aos gêneros discursivos, os inscritos nas disciplinas analisaram distintas obras, como livros didáticos $\mathrm{e}$ paradidáticos presentes no acervo do LEGEO (Laboratório de Ensino de Geografia UFF/Niterói) para a elaboração dos seus textos. Por fim, os grupos apresentaram suas produções para as suas respectivas turmas, a fim de realizar trocas e debates.

De forma concomitante, houve também o percurso metodológico das atividades realizadas pela monitora, que se deu da seguinte forma: (1) leituras e discussões teóricas acerca da natureza do conhecimento escolar e produção textual autoral (BARRETO, 2010; CARVALHO, 2002; COSTA, 2003; LOPES, 1999; MARANDINO, 2004; SARTI, 2012); (2) Acompanhamento pedagógico na realização dessas produções autorais em sala de aula (PPE II e PPE IV); (3) Apreciação/avaliação dos textos didáticos na forma de uma aula produzida em coparticipação com 0 professor/orientador; (4) Uma aula sobre Análise do Discurso e Produção Textual coministradas pela monitora com o referido professor orientador.

A pesquisa, de abordagem qualitativa, inscreve-se no âmbito do método da análise do discurso que de acordo com Orlandi (2005, 2009), é um campo da linguística que tem como proposta considerar e refletir sobre a relação da linguagem e dos signos com a ideologia presente nos discursos:

\footnotetext{
O discurso não é geral como a língua (ou a competência) nem individual e assistemático como a fala (ou performance). Ele tem a regularidade de uma prática, como as práticas sociais em geral. A análise de discurso introduz, por meio da noção de sujeito, a de ideologia e a de situação social e histórica. Ao introduzir a noção de história vai trazer para a reflexão as questões de poder e das relações sociais. O discurso é definido não como transmissor de informação, mas como efeito de sentido entre locutores. Assim, se considera que o que se diz não resulta só da intenção de um indivíduo em informar um outro, mas da relação de sentidos estabelecida por eles num contexto social e histórico. (ORLANDI, 2005, p. 60)
}

Partindo desta ideia de que a linguagem pressupõe a produção de sentidos e está escrita nas práticas sociais, ela está presente em qualquer espaço educativo: desde a escrita no quadro de giz até a gesticulação das professoras e professores, pois a linguagem é diversa e múltipla. Orlandi (1988) explicita que o discurso não é uma série de textos, e sim uma prática. Atribuída à linguagem, compreende-se o discurso como significação.

Costa (2004) analisa a escola e os currículos como território de produção, circulação e significação de significados. Logo, cultura, linguagem e discurso estão entrelaçados em qualquer produção textual e é por meio da escola que alguns desses discursos e significados são produzidos. Presente em qualquer espaço educativo, a linguagem pressupõe produção de sentidos e de discurso compreendido como significação. Segundo Godoy e Santos (2014) e Carvalho (2002), devemos nos atentar ao fato de que a cultura em seu sentido ideológico, sociológico e tecnológico igualmente depende da simbolização e, consequentemente, do discurso - ou seja, cultura e discurso estão inter-relacionados.

Assim, foi possível perceber ao longo das aulas, reflexões e debates, das análises de materiais didáticos e também no exercício da produção textual autoral a importância da atenção ao tipo de discurso que está engendrado em cada produção, pois é possível apreender a profunda articulação entre os objetivos educacionais e as linguagens desenvolvidas. 


\title{
Professores pesquisadores: textualidades nas práticas de ensino de geografia
}

A construção do saber escolar foi um dos debates que permeou os estágios de Pesquisa e Prática em Geografia II e IV. Ao partir do pressuposto que professores são produtores de conhecimento, o questionamento acerca do papel de professores da educação básica na construção do conhecimento escolar surgiu diversas vezes. Carvalho (2002) trabalha com a hipótese de que a construção de novas práticas está articulada, de forma mais intensa, com os discursos produzidos pela academia. Sarti (2012), por sua vez, detalha:

\begin{abstract}
A universidade desempenha, então, importante papel nesse processo e, devido à elevação do nível da formação docente e da sofisticação dos discursos pedagógicos, os segmentos acadêmicos atuantes nesse campo vivem hoje um momento de efervescência. Observa-se atualmente, pois, o estabelecimento de relações bastante privilegiadas entre dois dos vértices que compõem o triângulo da formação docente: poder público e universidade (relação que também inclui fundações e outros institutos ligados à pesquisa). [...] A cultura profissional partilhada no ambiente universitário está ancorada em valores e práticas acadêmicas que alcançam legitimidade social suficiente para nomear, descrever e explicar teoricamente fenômenos relacionados ao ensino, à aprendizagem, ao trabalho docente e à instituição escolar (SARTI, 2012. p. 330-333)
\end{abstract}

A autora aponta que a formação docente é como um triângulo, composta por três importantes atores em cada vértice: As universidades, o poder público e os professores. A relação entre os dois primeiros é mais estreita, enfatizando os saberes diretamente mais aplicáveis na prática, negligenciando aspectos da teoria educacional e o aprofundamento disciplinar, além de preconizar um modelo de formação docente transposta do mundo empresarial, baseado nas competências, conteúdos, desempenhos e capacidades.

Essa ressignificação do trabalho docente e da mediação didática também é apontada por Barreto (2010). A autora sugere que os primeiros mestres se caracterizavam pela produção de conhecimentos, saberes e reflexões, e que após o mercantilismo, a divisão social do trabalho promoveu uma reconfiguração, onde o professor era identificado pelo saber que transmitia, assumindo a tarefa de selecionar e organizar conteúdos de ensino. Desta forma, o professor ficou circunscrito a escolha do material didático que seria utilizado nas aulas, mercadoria cada vez mais pronta para ser consumida $^{1}$. A autora aponta ainda para uma configuração autoritária e institucionalizada do saber pedagógico, que supõe a legitimidade das informações transmitidas a rubrica da cientificidade.

Desta forma, surgiram os questionamentos que conduziram boa parte dos debates ao longo da disciplina. Mais uma vez, ressalta-se que o objetivo não é fazer crítica à prática dos professores e professoras da escola, e sim proporcionar outras perspectivas acerca da produção de conhecimento escolar: professores produzem conhecimento em suas práticas cotidianas.

Alguns dos conceitos que serão utilizados neste trabalho e que foram fios condutores durante as aulas e posteriormente nas análises dos textos didáticos são o de Mediação Didática (LOPES, 1997; 1999), Transposição Didática (LOPES, 1999; MARANDINO, 2004; MONTEIRO, 2001) e Recontextualização (MARANDINO, 2004).

A Mediação Didática, segundo Lopes (1997, 1999) seriam processos de constituição de realidades por meio de mediações contraditórias e relações complexas em sentido com a dialogia, sendo assim uma reconstrução dos saberes na instituição 
escolar. Para a autora, um dos aspectos centrais da mediação é o grande uso de metáforas e analogias.

\begin{abstract}
A mediação didática não deve, por conseguinte, ser interpretada como um mal necessário ou como um defeito a ser suplantado. A didatização não é meramente um processo de vulgarização ou adaptação de um conhecimento produzido em outras instâncias (universidades e centros de pesquisa). Cabe à escola o papel de tornar acessível um conhecimento para que possa ser transmitido. Contudo, isso não lhe confere a característica de instância meramente reprodutora de conhecimentos. O trabalho de didatização acaba por implicar, necessariamente, uma atividade de produção original. Por conseguinte, devemos recusar a imagem passiva da escola como receptáculo de subprodutos culturais da sociedade. Ao contrário, devemos resgatar e salientar o papel da escola como socializadora / produtora de conhecimentos. (LOPES, 1997, p. 566)
\end{abstract}

Marandino (2004) e Monteiro (2001) questionam o que diversos autores chamam de "saber sábio", como se a universidade fosse a única fonte do saber a ser ensinado. As autoras também debatem acerca da transposição didática, conceito que traz em sua concepção que o que se ensina na escola é uma mera transmissão, uma adequação do que se ensina nas universidades. Para Lopes (1999) a transposição didática pode ser associada ao movimento de transportar o conhecimento de um lugar ao outro sem fazer alterações.

[...] A compreensão dos aspectos constitutivos do conhecimento escolar e suas inter-relações com o conhecimento científico e o conhecimento cotidiano não podem ser aprofundadas sem que consideremos o entendimento do que vem a ser conhecimento, saber, ciência. Principalmente em um tempo em que a crise da razão faz-nos repensar nossas concepções de cientificidade, colocando em xeque, inclusive, nossas convicções a respeito da importância do conhecimento, o aprofundamento filosófico nos permite revalorizar, em novas bases, o saber escolar. (LOPES, 1999, p. 171)

Já na Recontextualização, segundo Marandino (2004, p. 103) age de uma forma seletiva, onde há a apropriação e a refocalização do discurso, "relacionando outros discursos a partir de sua própria ordem, tornando-os um outro discurso". Para a autora, a diferença entre a Recontextualização e a Transposição Didática se dá na compreensão do papel social na transformação do conhecimento científico, na produção do saber e no discurso pedagógico, onde o discurso de ordem social é legitimador.

[...] o foco é estudar a transferência dos textos entre diferentes contextos de produção e reprodução, mediada pelas relações de poder e pela regulação do discurso de ordem social: há aqui a produção de um discurso com características de discurso recontextualizador, o discurso pedagógico, sendo que o discurso regulativo se sobrepõe ao instrucional. (MARANDINO, 2004, p. 104)

Lopes (1999) manifesta a importância da valorização do saber escolar, e é nesse movimento que se inscreve a importância da produção autoral de materiais didáticos, pois o saber escolar não é a aplicação do conhecimento acadêmico, e sim um novo conhecimento, onde o professor ao elaborar e desenvolver conteúdos escolares é também produtor e agente desse processo de novos marcos epistemológicos.

Carvalho (2002) questiona se de fato a escola fornece condições para formar estudantes leitores e produtores de textos críticos e criativos. Neste trabalho, questionamos se a universidade e a própria escola fornecem condições para as/os 
futuras/os e atuais professores. Estas reflexões também nortearam as discussões ao longo das aulas de Pesquisa e Prática de Ensino II e IV.

\section{Produção textual autoral: autonomização de saberes}

Ao longo do processo de confecção dos textos didáticos uma das prioridades foi a de atentar as alunas e alunos, a todo o tempo, em relação aos discursos e às múltiplas linguagens e gêneros textuais que permeiam os materiais didáticos, tais como: Fotos, tirinhas, estórias, reportagens, mapas, desenhos, entre outros. As/os discentes, ao analisarem os livros didáticos, perceberam também as diferentes diagramações possíveis para a confecção de seus materiais.

A escolha dos conceitos e conteúdos do currículo de geografia foi livre, com a obrigatoriedade apenas de pertencerem aos componentes curriculares de Geografia trabalhados no $2^{\circ}$ segmento do Ensino Fundamental $\left(6^{\circ}\right.$ ao $9^{\circ}$ anos). Já para as turmas de PPE IV o elemento central de reflexão foi a diversidade e as diferenças a partir da geografia escolar. Serão descritos aqui os temas abordados nos textos.

Os trabalhos da turma que cursou o estágio de Pesquisa e Prática de Ensino II em 2017.1 foram dos mais diversos, perpassando pelos discursos da recontextualização $\mathrm{e}$ da transposição didática. Esta turma teve um total de cinco trabalhos $\mathrm{e}$ respectivamente cinco grupos, que serão chamados aqui de A, B, C, D, E.

Em seu texto didático o grupo "A" redigiu um texto para o $7^{\circ}$ ano do ensino fundamental, a partir da estória de Bruninho, um taxista que morava no bairro de Campo Grande, localizado na Zona Oeste da cidade do Rio de Janeiro, mas às vezes rodava com seu carro pelo bairro de Copacabana, Zona Sul da mesma cidade, mesclando de forma lúdica os conceitos geográficos e a realidade social de pessoas que moram afastadas do Centro e da Zona Sul da cidade. A partir do texto foram apresentados e trabalhados, de forma introdutória, os seguintes conceitos: mobilidade urbana - em dado momento do texto, há um diálogo do taxista com um passageiro, acerca do trânsito cada vez mais comum em vários pontos da cidade, além da superlotação de meios de transporte como ônibus, trem, metrô e BRT; e o conceito de migração pendular, a partir do momento que Bruninho roda em cidades da região metropolitana para atender um maior número de passageiros. Ambos os conceitos foram grifados ao longo do texto, e explicados de forma introdutória em "boxes" explicativos, como os que estão presentes na diagramação de alguns livros didáticos. O grupo utilizou também imagens ilustrativas e recortes de jornais, trazendo um pouco de questões acerca da mobilidade urbana, mesclando diferentes linguagens em sua produção textual, além de um discurso que trouxe diversos questionamentos e reflexões, pautado principalmente na recontextualização.

Já o grupo "B" trouxe uma ampla discussão acerca da América Latina, conteúdo geralmente trabalhado no $8^{\circ}$ ano do ensino fundamental, e de forma introdutória o conceito de região. A partir de um discurso recontextualizador e tratando temáticas atuais, as/os componentes se inspiraram nos capítulos de livros didáticos para tratar da temática, utilizando diagramação bem similar a que comumente vemos em alguns livros. Com uma linguagem escrita simples, o grupo mesclou diferentes linguagens em sua produção autoral, como reportagens, imagens diversas, mapas, letras de músicas, tirinhas - e com uma enorme preocupação de reflexões referentes aos povos originários das mais diversas regiões da hoje chamada de América Latina e de suas resistências, como por exemplo, a partir de dados que mostravam que o idioma Quechua ainda é muito falado no Peru. 
Com um texto intitulado "A viagem de Severino", o grupo "C" mesclou a estória do avô de um dos integrantes do grupo com os conceitos e conteúdos a serem trabalhados no texto didático: Migração, êxodo rural, ciclo da borracha, modernização do campo e industrialização. A estória mostrava e se construía a partir da realidade vivida por Severino - nome fictício - ao migrar para Manaus em 1879, perpassando pela modernização no campo, industrialização no período Vargas, ditadura militar, até chegar aos dias de hoje. A partir de um tom crítico e de um discurso Recontextualizador, o material didático trouxe ao fim atividades propostas, como perguntas relacionadas ao que foi lido ao longo do texto, explicitando também ao final do trabalho que se tratava de um conteúdo a ser trabalhado com turmas de $7^{\circ}$ ano do ensino fundamental.

O grupo " $\mathrm{D}$ " trouxe questionamentos a partir de um conteúdo de $6^{\circ}$ ano: climatologia, mais especificamente as mudanças climáticas e o efeito estufa. A partir de um discurso Recontextualizador, o texto trouxe questionamentos acerca das mudanças nos efeitos climáticos, perpassando por políticas de preservação ambiental e a arborização das cidades - utilizando gráficos e imagens de filmes para corroborar com a produção autoral. $\mathrm{O}$ grupo trouxe uma proposta de atividade, um júri simulado sobre aquecimento global, onde metade da turma seria à favor de que o fenômeno está sendo acelerado pelos seres humanos e a outra metade seria à favor de que este se trata apenas de um fenômeno natural. A proposta de júri simulado perpassa pela Recontextualização e pela mediação didática, a partir do momento que trás consigo as idéias de dialogismo e polifonia.

A partir da Transposição Didática, o grupo "E" utilizou os conceitos de forma, função, processo e estrutura a partir de Milton Santos, trazendo também uma discussão acerta do urbano "ser" o contrário de rural. Como exemplo, o grupo utilizou alguns locais do Centro do Rio de Janeiro, que constituem a mesma forma, porém com funções diferentes. Outros conceitos trabalhados pelo grupo foram a urbanização e especulação imobiliária.

Já nas turmas de Pesquisa e Prática de Ensino IV, o fio condutor foi a diversidade e as diferenças numa perspectiva geográfica. As textualidades nesta turma produzidas por quatro trios, que aqui serão chamados de $\mathrm{F}, \mathrm{G}, \mathrm{H}$, I, tendo a como o discurso que perpassou todos os trabalhos.

O grupo " $F$ " trouxe as questões étnico-raciais no Brasil como eixo central de sua produção autoral, abordando também questões como o mito da democracia racial e o racismo institucionalizado. A partir de um texto explicando sobre a temática, o trio utilizou reportagens e leis que corroboravam com o tema, assim como uma diagramação parecida com a de livro didático, contendo dicas de filmes e músicas relacionadas à temática. Foram feitos vários questionamentos e perguntas, a fim de instigar quem estivesse lendo o trabalho, gerando reflexão e contendo teor crítico.

$O$ trio " $G$ " trouxe discussões acerca da cultura e da identidade a partir de reflexões acerca da representação do Oriente Médio, trazendo questionamentos e indagações, como se estivesse trazendo a pessoa que está lendo para interagir, mesmo sendo um texto escrito. Questionamentos como "porquê de o oriente ser chamado de oriente", "Por que não chamamos parte dos nossos mapas de Mundo Cristão?" e a diferenciação entre árabe e muçulmano foram essenciais para desconstruir o reducionismo que se tem no imaginário sobre o Oriente Médio. Já o trio "H" trouxe a partir de imagens, mapas, tabelas e gráficos o trio " $\mathrm{H}$ " reflexões acerca do que acontece hoje com povos originários brasileiros.

Por meio de uma tirinha, relatando a vida de Felipe, um menino que saiu do campo para ir morar na cidade, o grupo "I" trabalhou com os conceitos de campo, 
cidade, agronegócio, soberania alimentar e agricultura camponesa. Mesclando a tirinha com um texto didático escrito, o trio trouxe questionamentos e reflexões acerca dos alimentos que chegam em nossas mesas e os modos de produção.

Assim, grande parte dos textos didáticos autorais possuíram um caráter crítico, instigando posicionamentos ao leitor acerca dos mais variados temas e conceitos ligados à Geografia Escolar. Na maioria das produções os estudantes tiveram o cuidado de buscar um discurso Recontextualizador (MARANDINO, 2004), além de uma preocupação para explicar os conceitos acadêmicos da Geografia utilizados. No entanto, o gênero discursivo predominante ainda foi o dissertativo-argumentativo: apenas um dos textos didáticos trouxe uma tirinha autoral, fugindo do padrão dos textos dissertativos.

Houve dificuldade em desenvolver tais produções junto com os professores regentes das turmas escolares do estágio supervisionado. Apontamos algumas das possíveis causas desta dificuldade como o tempo hábil para a confecção dos textos e sua aplicação nas salas de aula diante do calendário escolar. Apenas um aluno da turma de Pesquisa e Prática de Ensino II conseguiu apresentar a produção de seu grupo em uma aula do estágio supervisionado e segundo o mesmo o retorno foi positivo, gerando debates e instigando reflexões dentro de sala de aula. É importante lembrar que este trabalho realizado na Pesquisa e Prática de Ensino de Geografia é um processo em constante construção e movimento.

\section{Considerações finais}

A partir dos textos didáticos produzidos pelas alunas e alunos de PPE II e IV, e pelos seus relatos em sala de aula, foi possível perceber como a produção autoral é um importante exercício de pesquisa do professor, sem deixar de considerar os outros saberes e discursos que "cruzam" a escola tal como o discurso pedagógico. Logo, os saberes escolares são saberes Recontextualizados (BERSTEIN, 2000).

Segundo Barreto (2010, p. 219) "A presença de múltiplas linguagens constitui uma alternativa de ruptura com os limites impostos pelas velhas tecnologias utilizadas, representadas principalmente pelo quadro de giz e pelos livros didáticos, bem como pelo arranjo tradicional das salas de aula". Concorda-se aqui que as textualidades autorais, mescladas com diferentes linguagens - como letras de músicas, mapas, gráficos, reportagens, tirinhas, entre outras - são também de suma importância nas textualidades autorais, e dependendo da forma que for conduzida a atividade a partir das textualidades, trazer a possibilidade de diálogos, reflexões e questionamentos a partir destas diferentes linguagens.

O conhecimento de referência não deixou de ser importante, pois é a partir dele que realizamos a Mediação Didática (LOPES, 1997). Sem esse, a epistemologia escolar tornar-se-ia "única". Entretanto, a partir da estratégia pedagógica em tela, percebemos a persistência da percepção de que ainda a Geografia Escolar é exclusivamente informada pela "Geografia Universitária" por parte das/os nossas/os licenciandas/os conforme as avaliações empreendidas ao final do período letivo acadêmico.

A produção autoral por meio de textos didáticos autorais pode ser vista como ruptura à concepção "aplicacionista" dos saberes escolares como ocorre, por exemplo, no caso da transposição didática (MARANDINO, 2004). Nesse sentido, a produção autoral pode ser um recurso e estratégia pedagógica para quem está em seus primeiros contatos com a docência quanto para quem já é professor. Portanto, em última instância, a produção autoral docente pode ser entendida como empoderamento das práticas 
pedagógicas, dando autonomia para o professor no sentido da produção do conhecimento escolar desde que mediado pelas demandas sociais.

\section{Agradecimentos}

Agradecemos à Universidade Federal Fluminense (UFF) e à Pró-Reitoria de Graduação da Universidade Federal Fluminense pelo investimento realizado no projeto de "Pesquisa e Prática de Ensino em Geografia: Autonomização e produção de saberes". A todas as alunas e alunos que cursaram o estágio de Pesquisa e Prática de Ensino II e IV e que tornaram possível a realização desse trabalho.

\section{Notas}

1 - O objetivo deste artigo não é se aprofundar nas críticas à mercantilização da educação e do Livro Didático. Recomenda-se neste trabalho a leitura do artigo "Material didático sob a lógica do mercado: uma questão de política educacional” de Andrade e Cária (2011).

\section{Referências bibliográficas}

ANDRADE, Nelson; CÁRIA, Neide. Material didático sob a lógica do mercado: Uma questão de política educacional. Recuperado de:

<http://www.anpae.org.br/simposio2011/cdrom2011/PDFs/trabalhosCompletos/comunicacoesRelatos/0419.pdf>

BARRETO, Raquel. A apropriação educacional das tecnologias da informação e da comunicação. In: LOPES, Alice Casimiro; MACEDO, Elizabeth. (Orgs.). Currículo: debates contemporâneos. São Paulo: Ed. Cortez, 2010.

BERSTEIN, Basil. Pedagogy, symbolic control and identity. British Journal of Sociology Education. Londres, $\mathrm{n}^{\circ} 18$ (1), p. 119-124.

BEZERRA, Amélia Cristina. Tecendo caminhos e afirmando sentidos entre cidadania, espaço e geografia escolar. Rev. Tamoios, São Gonçalo (RJ), ano 12, n. 2, p. 22-31, jul/dez. 2016.

CALLAI, Helena. Temas e conteúdos no ensino de Geografia. In: RABELLO, K; BUENO, M. (org) Currículo, políticas públicas e ensino de Geografia. Goiânia: Ed. da PUC Goiás, 2015. p. 213-230.

CARVALHO, José Ricardo. Leitura e Produção textual no Espaço Escolar. Niterói: Muiraquitã, 2002.

CAVALCANTI, Lana. O ensino de geografia na escola. São Paulo: Papirus, 2012.

COSTA, Carmen Lúcia. A Ausência e a presença do debate de gênero na Geografia do Ensino Fundamental e Médio. Revista Latino-americana de Geografia e Gênero. Ponta Grossa, v2, n2, p. 7684, ago/dez, 2011.

COSTA, Marisa Vorraber. (Org). O Currículo nos limiares do contemporâneo. Rio de Janeiro: DP\&A, 2003.

GODOY, Elenilton; SANTOS, Vinício. Um olhar sob a cultura. Educação em Revista, v. 30 nº 3 . Belo Horizonte: jul-set 2014.

LOPES, Alice Casimiro. Conhecimento escolar: Ciência e cotidiano. Rio de Janeiro: EdUERJ, 1999.

Conhecimento escolar em química: Processo de mediação didática da ciência.

Rio de Janeiro: Química nova, 20(5), 1997.

MARANDINO, Martha. Transposição ou recontextualização? Sobre a produção de saberes na educação em museus de ciências. São Paulo: Revista Brasileira de Educação, no 26, 2004.

MONTEIRO, Ana Maria. Professores: Entre saberes e práticas. Educação \& Sociedade, ano XXII, $\mathrm{n}^{\circ}$ 74, Abril/2001.

ORLANDI, Eni. Análise de Discurso. Campinas: Pontes, 2005. 
Discurso e Leitura. São Paulo: Cortez, 1988.

. O que é linguística. São Paulo: Brasiliense, 2009.

RIVERA, José Armando Santiago. LOS ESCENARIOS DE LA COTIDIANIDAD, LA EDUCACIÓN GEOGRÁFICA Y LA COMPLEJA REALIDAD GLOBALIZADA. Revista Brasileira de Educação em Geografia, Campinas, v. 5, n. 9, p.04-28, jan./jun., 2015.

SARTI, Flavia. O Triângulo da formação docente: seus jogadores e configurações. Educação e Pesquisa, v. 38, nº 2. São Paulo: abr-jun 2012. 